\title{
SISTEM INFORMASI DAN ANALISA GEMPABUMI MENGGUNAKAN JISVIEW PADA STUDI KASUS GEMPABUMI TASIKMALAYA
}

\author{
Reza Muflihendri Widyarta ${ }^{1}$, Wiko Setyonegoro ${ }^{2}$, Januar Arifin ${ }^{3}$ \\ ${ }^{1}$ Program Studi Geofisika, Universitas Indonesia, 16424 Depok, Jawa Barat, Indonesia \\ ${ }^{2}$ Pusat Penelitian dan Pengembangan BMKG, Jl. Angkasa I No.2 Kemayoran Jakarta Pusat 10720 \\ ${ }^{3}$ Pusat Gempabumi dan Tsunami BMKG, Jl. Angkasa I No.2 Kemayoran Jakarta Pusat 10720 \\ email: rezamufli@gmail.com ${ }^{1}$, wiko_setyonegoro@yahoo.co.id ${ }^{2}$, jarcorp@ yahoo.com ${ }^{3}$
}

Article history

Received May 10, 2020

Revised May 13, 2019

Accepted May 28, 2019

Available online May 31, 2020

Keywords

Earthquake

JISView

Subduction Zone

Earthquake parameters

Focal Mechanism

Riwayat

Diterima 10 Mei 2020

Revisi 13 Mei 2020

Disetujui 28 Mei 2020

Terbit 31 Mei 2020

Kata Kunci

Gempa Bumi

JISView

Zona Subduksi

Parameter Gempa

Mekanisme Fokal

\begin{abstract}
Java Island has an interesting tectonic system to study, especially since this region is formed from plate collisions that cause the formation of subduction zones. Because of the uniqueness, earthquakes often occur in this region, which one of them became the attention of researchers, namely the Tasikmalaya earthquake on December 15, 2017. The purpose of this study is to analyze the earthquake recording signals and also the pattern of focal mechanisms of the Tasikmalaya earthquake from processing result of JISView (BMKG) devices that have been validated with comparators from GFZ (Germany) and USGS (United States) websites. The method used is to make an analysis of the wave signal caught by the recorder station and then identify the results of the parameters generated on the calculation of the device and match the data obtained with data tectonic structure around the area of the earthquake zone. Based on the results of data processing, the intensity value of earthquake signals obtained from the processing in accordance with the data released by BMKG agencies and earthquakes from the depth of $90-110 \mathrm{~km}$ which occurs due to the shift of the fault, with the type of fault is strike-slip fault (dextral), where the cause of the earthquake comes from the subduction zone (benioff zone in the deep background).
\end{abstract}

\section{Abstrak}

Pulau Jawa memiliki sistem tektonik yang menarik untuk dikaji, terutama karena wilayah ini terbentuk dari tumbukan lempeng yang menyebabkan terbentuknya zona subduksi. Karena keunikan tersebut, tak jarang sering terjadi gempa bumi di wilayah ini, yang mana salah satunya menjadi perhatian dari peneliti, yaitu gempa Tasikmalaya pada tanggal 15 Desember 2017. Tujuan penelitian ini adalah untuk menganalisa sinyal rekaman gempa dan juga pola mekanisme fokal dari gempa Tasikmalaya dari hasil pengolahan perangkat JISView (BMKG) yang telah divalidasi dengan pembanding dari website GFZ (Jerman) dan USGS (Amerika Serikat). Metode yang dipakai adalah dengan membuat analisa dari sinyal gelombang yang tertangkap oleh stasiun perekam kemudian melakukan identifikasi pada hasil parameter yang dihasilkan pada perhitungan perangkat dan mencocokkan data yang didapat dengan data struktur tektonik daerah sekitar zona gempa. Berdasarkan hasil pengolahan data, nilai intensitas sinyal gempa yang didapat dari hasil pengolahan sesuai dengan data yang dikeluarkan oleh lembaga BMKG serta gempa berasal dari kedalaman antara 90-110 km yang mana terjadi akibat terjadinya pergeseran sesar, dengan jenis sesar yaitu strike-slip fault (dextral), dimana penyebab gempa berasal dari zona subduksi (zona benioff di deep background).

\section{PENDAHULUAN}

Indonesia adalah salah satu negara di dunia dengan struktur tatanan tektonik aktif, dikarenakan negara ini terbentuk dari hasil pertemuan antara tiga lempeng (mega triple junction). Tiga lempeng utama tersebut yaitu Lempeng Indo-Australia yang bergerak ke 
utara, Lempeng Eurasia yang bergerak ke tenggara, dan Lempeng Pasifik yang bergerak ke arah barat, bertemu pada satu simpang tiga (triple junction) yang terletak di selatan Kepala Burung, Papua. (Verstappen, 2010)

Kondisi tersebut menjadikan Indonesia sebagai sebuah daerah tektonik aktif dengan tingkat seismisitas (kegempaan) yang tinggi. Salah satu bentukan tektonik dapat terlihat di bagian selatan pulau jawa, dimana di bagian tersebut terbentuk zona subduksi (hasil tunjaman kerak samudera dan kerak benua) antara lempeng Indo-Australia dan lempeng Eurasia yang mana sampai sekarang masih tercatat pergerakannya. Tidak hanya subduksi, di bagian penunjaman juga diketahui terdapat beberapa sesar aktif yang salah satunya juga banyak menimbulkan gempa bumi. Salah satu dari hasil pergerakan tersebut adalah kejadian gempa di Tasikmalaya pada tanggal 15 Desember 2017.

Menurut sumber data BNPB tahun 2017 Dampak gempa tersebut menyebabkan 4 orang meninggal dunia, 11 orang luka berat, 25 orang luka ringan, 451 rumah rusak berat, 579 rumah rusak sedang, dan 1.905 rumah rusak ringan. Selain itu juga terdapat kerusakan 46 unit sekolah/madrasah, 38 unit tempat ibadah, 9 kantor, dan 4 rumah sakit dan puskesmas. Daerah yang paling parah mengalami kerusakan terdapat di 4 daerah yaitu Kota Tasikmalaya, Kabupaten Tasikmalaya, Kabupaten Ciamis dan Kabupaten Pangandaran. (BNPB, 2017)

\section{Tektonik Pulau Jawa}

Seismisitas di Pulau Jawa didominasi oleh gempa yang berkaitan dengan subduksi dan sesar-sesar di darat. Elemen paling penting pada kenampakan tektonik di Jawa adalah terdapatnya palung Jawa yang berorientasi dari Barat Laut (di depan Sumatra) hingga berarah ke Timur untuk kepulauan Sunda Lesser. Palung tersebut merepresentasikan suatu batas pelat konvergen yang dibengkokkan yang mana berhubungan dengan zona Benioff yang berlanjut dengan arah timur menuju busur Banda. Zona penunjaman di Jawa Barat termasuk dalam penunjaman pendek, yaitu sejauh $180 \mathrm{~km}$ dengan sudut $25^{\circ}$. (Tim Pusat Studi Gempa Nasional, 2017)

Dari data Kementerian PUPR, secara umum struktur geologi aktif di Jawa didominasi oleh sesar geser dan sesar naik dengan sesar turun sebagai struktur minor. Beberapa sesar utama di
Jawa yang sudah banyak diketahui antara lain Sesar Cimandiri, Sesar Lembang, dan Sesar Baribis-Citanduy. Di Jawa bagian tengah dan timur, struktur yang terlihat dominan adalah struktur sesar naik (zona Sesar Kendeng dan Semarang), sedangkan di bagian timur Jawa diwakili oleh sistem patahan turun (Sesar Pasuruan, Probolinggo, dan Baluran). (Tim Pusat Studi Gempa Nasional, 2017)

\section{Mekanisme Sumber Gempa Bumi}

Melalui data seismogram, dapat diketahui banyak informasi gempa bumi berikut dengan parameter gempa bumi seperti: magnitudo, kedalaman, lokasi, waktu, asal gempa bumi termasuk juga mekanisme fokus. Mekanisme sumber gempa bumi (focal mechanism) adalah suatu istilah yang digunakan untuk menerangkan sifat penjalaran energi gempa bumi yang berpusat pada hiposenter atau fokus gempa bumi. Sesar sering disebut sebagai mekanisme penjalaran energi gelombang elastis pada fokus tersebut, sehingga dengan memperoleh arah gerakan sesar dan arah bidang sesar suatu gempa bumi, maka akan diperoleh mekanisme sumber gempa bumi. (Ismiwati,2011)

Berdasarkan dengan arah pergerakan yaitu nilai Strike $(\Phi)$, Dip $(\delta)$, dan Rake $(\lambda)$, sesar dapat diklasifikasikan menjadi 4 jenis, yaitu:

a. Sesar Turun (normal fault), jenis sesar dimana hanging wall pada sesar relatif turun terhadap foot wall. Parameter jenis ini akan memenuhi nilai $\delta \neq 0$ atau $\delta \neq \pi / 2$, serta nilai $\lambda$ terletak pada rentang $(-\pi, 0)$. 


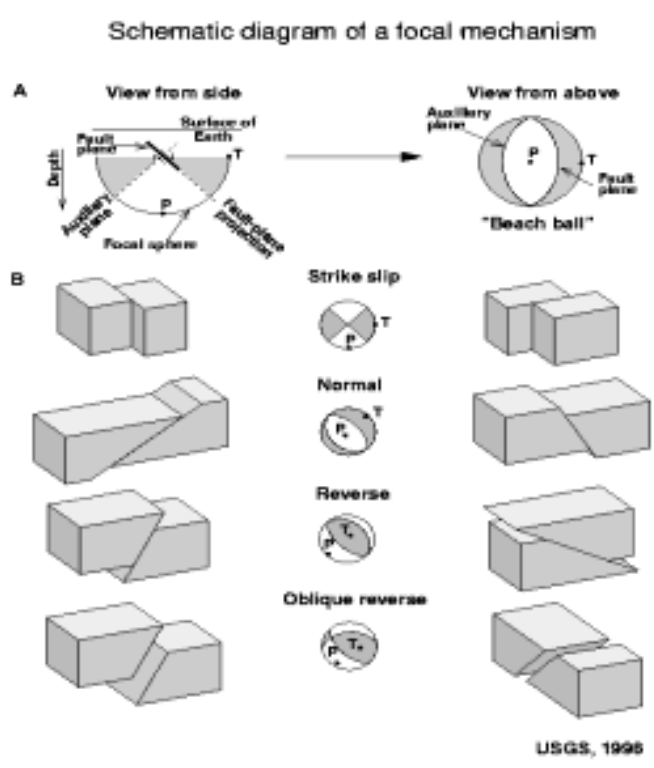

Gambar 1. Ilustrasi diagram sesar dan pola makanisme fokal.

b. Sesar Naik (thrust/reverse fault), jenis sesar dimana hanging wall pada sesar relatif naik terhadap foot wall. Parameter jenis ini akan memenuhi nilai $\delta \neq 0$ atau $\delta \neq \pi / 2$, serta nilai $\lambda$ terletak pada rentang $(\pi, 0)$.

c. Sesar Mendatar (strike slip fault), jenis sesar dengan arah gerakan yang relatif mendatar antar satu bidang dengan bidang lainnya. Parameter jenis ini akan memenuhi nilai $\delta=$ $\pi / 2$, serta nilai $\lambda=0$ atau $\lambda=\pi / 2$, sesar ini terbagi menjadi 2 , yaitu:

- Left strike slip lateral fault (sinistral strike slip fault), apabila hanging wall bergerak kekiri dan nilai $\lambda=0$.

- Right strike slip lateral fault (dextral strike slip fault), apabila hanging wall bergerak ke kanan dan nilai $\lambda=\pi=180$

d. Sesar kombinasi (oblique fault), jenis sesar yang merupakan gabungan antara ketiga jenis sesar.terletak pada rentang $(\pi, 0)$.

\section{METODE PENELITIAN}

Tahap inti dalam pengolahan data meliputi :

a. Mencari data gempa sesuai dengan waktu dan tanggal kejadian.

b. Analisis struktur tektonik (pola focal mechanism) dan data sinyal gempa (spectrum, displacement, velocity, acceleration).

c. Perbandingan parameter mekanisme gempa bumi.

\section{Data Penelitian}

Data yang digunakan pada penelitian mencakup 15 data sinyal gempa yang terekam di stasiun gempa terdekat, dimana posisi gempa yang dianalisa berada di koordinat 108.047 Lintang Timur dan 8.06 Lintang Selatan, sekitar $42 \mathrm{Km}$ Barat Daya Kawalu, Jawa Barat, dengan kedalaman sampai $91 \mathrm{~km}$, magnitudo 6.86 Skala Richter dan terjadi 15 Desember 2017 pukul 16:47:58.17 UTC. (BMKG, 2017)

\section{Perangkat JISView}

JISView (Japan-Indonesia Network System Viewer) merupakan software yang dikembangkan untuk menggambarkan informasi gempabumi secara near realtime yang berpotensi menimbulkan kerusakan dan bangunan, infrastruktur vital dan berbagai fasilitas umum. Sejak tahun 2011, Puslitbang telah mengembangkan software JISView ini agar mampu menentukan mekanisme sumber gempabumi secara cepat, sekitar 5 sampai 7 menit setelah kejadian gempabumi. (Nugraha, Arifin, Setyonegoro , Hardy, Susilanto, 2013)

Pada pengolahan ini, JISview yang dipakai adalah jenis LINUH versi 1.0.2. Untuk mendownload data sinyal stasiun, JISView ini terhubung dengan jaringan ARCLINK (gambar 2a) yang merupakan penyedia data stasiun perekam sinyal gempa berbasis real time.

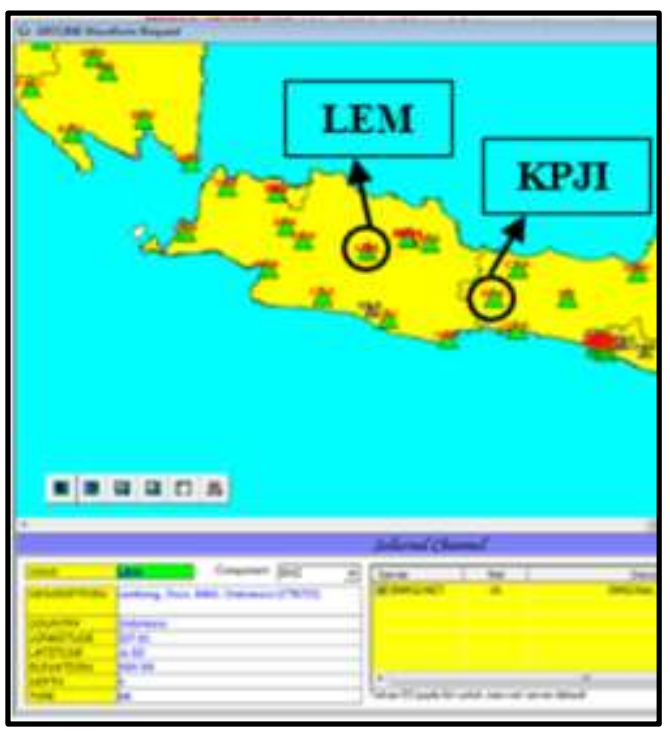

Gambar 2. Tampilan Jaringan Data ARCLINK pada JISView. Berikut lokasi Stasiun monitoring gempabumi LEM dan KPJI 


\section{Pengolahan Data}

Data dalam penelitian ini meliputi data sinyal gempa bumi Tasikmalaya tanggal 15 Desember 2017, data hiposenter yang meliputi data koordinat (longitude, latitude), kedalaman, magnitudo, waktu terjadinya gempa, data nama stasiun, data waktu tiba gelombang di setiap stasiun dan model kecepatan gelombang P.

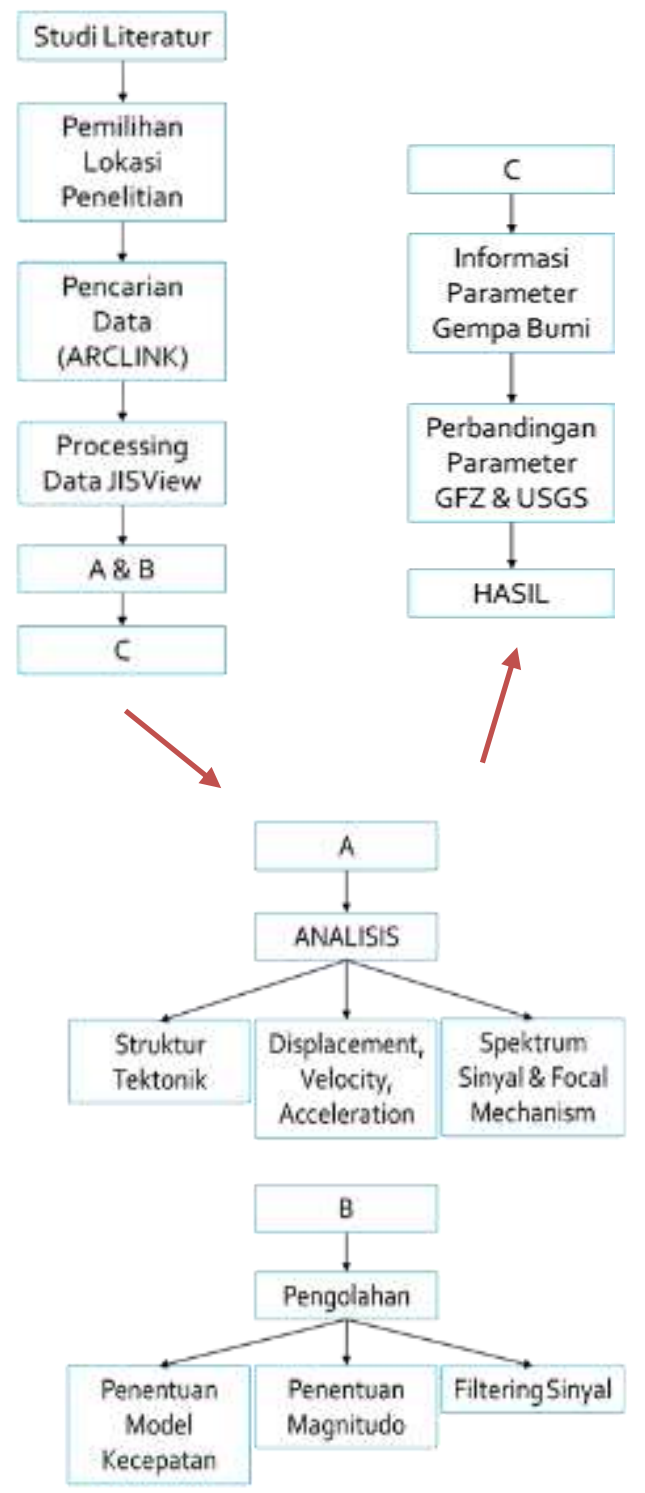

Gambar 3. Diagram alur penelitian.

Secara deskriptif tahap pengolahan data dapat diuraikan sebagai berikut:

1. Pemilihan data stasiun perekam yang masih tercangkup/dekat dengan zona gempa melalui ARCLINK.
2. Data sinyal akan dipilih berdasarkan kondisi data, dimana ada beberapa data stasiun yang merupakan ghost event (tidak ada data), sehingga perlu dihapus dari wilayah pengolahan.

3. Melakukan signal picking, yaitu untuk menentukan jenis gelombang $\mathrm{P}$ dan $\mathrm{S}$ dari sinyal yang terekam.

4. Melakukan perhitungan parameter gempa, dimana ada 2 jenis parameter yang dihitung yaitu parameter kinematik (waktu, koordinat, kedalaman, jarak episentrum dengan kota terdekat) dan dinamik (nilai magnitudo gempa).

5. Melakukan filtering signal pada IIR Butterworth Filter agar tampilan data lebih akurat.

6. Penentuan model kecepatan, menggunakan IASP91 yang ada pada salah satu menu di JISView.

7. Setelah didapatkan hasil pengolahan parameter JISView yang terakhir, maka akan dilakukan perbandingan parameter dengan 2 web pembanding yaitu GFZ (Jerman) dan USGS (Amerika Serikat).

Diagram alur metoda pengolahan data adalah sebagai berikut:

\section{HASIL DAN PEMBAHASAN}

Terdapat analisis data yang perlu dilakukan dengan mengambil contoh dari data sinyal gempa yang didapat dari minimal 2 stasiun yang berada di dekat area gempa. Kedua stasiun tersebut adalah stasiun pengamatan Karang Pucung, Jawa, Indonesia (KPJI) dan stasiun pengamatan Lembang, Jawa, Indonesia (LEM) (gambar 2). Dari data Kementerian PUPR tahun 2017, untuk wilayah daerah Lembang (LEM), terdapat sesar yang memanjang dari BaratTimur terletak di utara Kota Bandung di Jawa Barat. Berdasarkan studi geodesi, Abidin dkk. (2008, 2009) memperkirakan slip rate sesar Lembang sebesar 3-14 $\mathrm{mm} / \mathrm{th}$ dengan pergerakan geser sinistral (Abidin, Andreas, Gamal, Wirakusumah, Darmawan, Deguchi \& Maruyama, 2008). Kemudian untuk wilayah sekitar daerah Cilacap (KPJI) menurut data dari Badan Geologi tahun 2009, daerah tersebut dikontrol oleh seismotektonik sesar mendatar mengiri Serayu, dan lajur seismotektonik 
tunjaman selatan Jawa. (ESDM. 2009) Zona subduksi ini adalah jalur pertemuan lempeng oseanik Australia yang bergerak ke utara pada kecepatan $7 \mathrm{~cm} /$ tahun dengan lempeng kontinental Eurasia yang stabil dan menjadi landasan Pulau Jawa (Sutrisna. 2015).

\section{Analisis Sinyal Spektrum}

Dapat dilihat pada gambar 4 dan 5 bahwa spektrum yang rapat akan menunjukkan besarnya energi gempabumi, pada stasiun KPJI nilai frekuensi puncak terjadi di $0.4 \mathrm{~Hz}$.

\section{a. $\mathrm{KPJI}$}

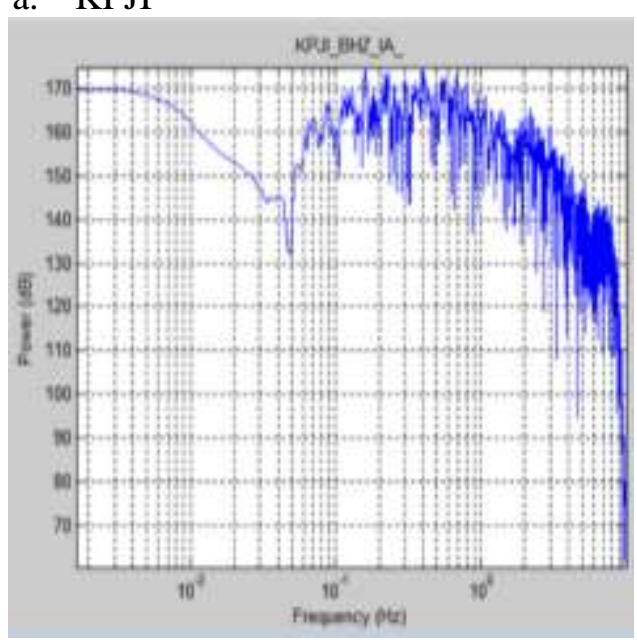

Gambar 4. Sinyal spektrum stasiun KPJI

Sedangkan stasiun LEM nilai frekuensi puncak nya berada pada nilai $0,1 \mathrm{~Hz}$. Kedua nilai tersebut berada pada rentang kekuatan 170-180 dB. Data analisis sinyal spektrum tsb bisa digunakan sebagai acuan dalam pengerjaan konstruksi, terutama pada tahanan daya yang nilai frekuensi nya telah disesuaikan agar lebih tinggi dari nilai frekuensi puncak pada sinyal gempa pada daerah yang diteliti.

\section{b. LEM}

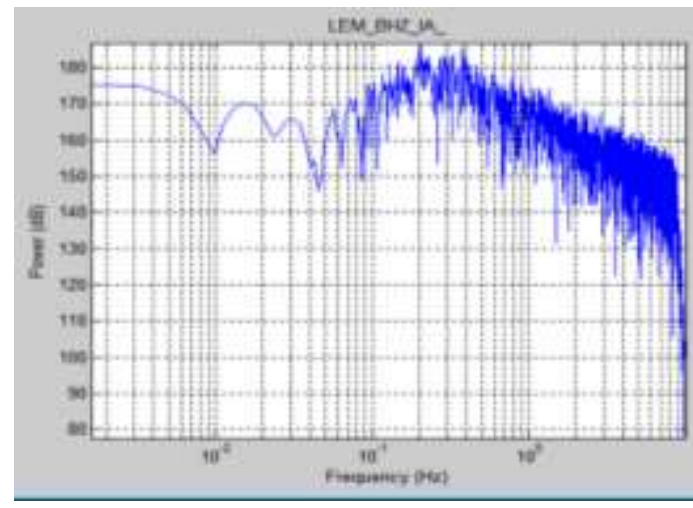

Gambar 5. Sinyal spektrum stasiun LEM

\section{Analisis Displacement, Velocity, dan Acceleration}

Parameter-parameter gempa bumi yang lain dapat berupa simpangan kecepatan (velocity), simpangan (displacement) dan percepatan (acceleration). Perpindahan materi dalam perjalaran gelombang seismik biasa disebut simpangan (displacement).

\section{a. Displacement}

\section{- KPJI}

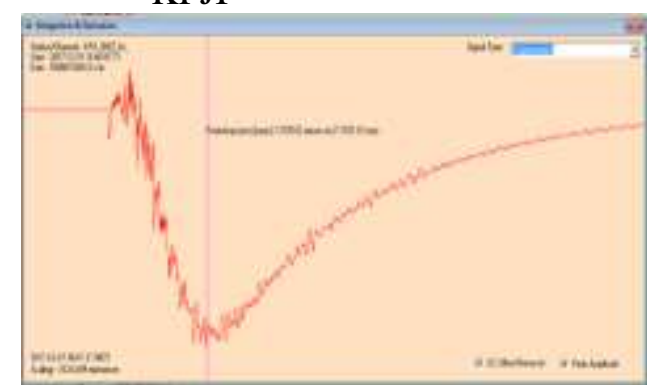

Gambar 6. Sinyal spektrum Displacement stasiun KPJI

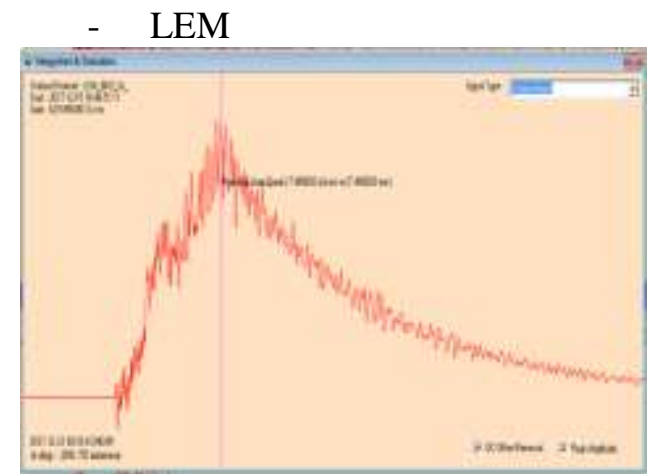

Gambar 7. Sinyal spektrum Displacement stasiun LEM 


\section{b. Velocity}

- KPJI

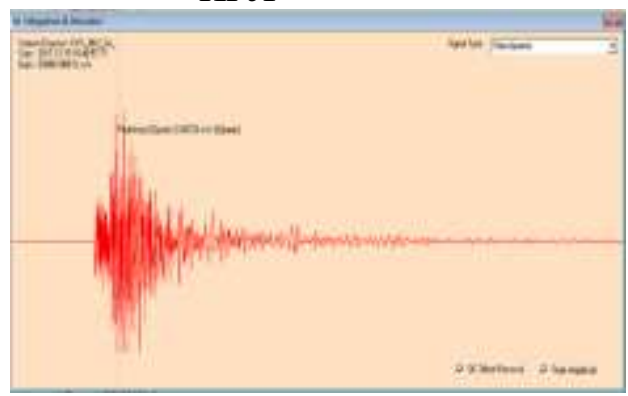

Gambar 8. Sinyal spektrum Velocity stasiun KPJI

Jika kita lihat waktu yang diperlukan untuk perpindahan tersebut, maka kita bisa tahu kecepatan materi tersebut. Sedangkan percepatan (acceleration) adalah parameter yang menyatakan perubahan kecepatan mulai dari keadaan diam sampai pada kecepatan tertentu. (Ismiwati,2011)

Dapat dilihat dari gambar 6 dan 7 jika spektrum displacement pada stasiun KPJI memiliki nilai peakAmp 7.797E02 micron meter atau 7.797E$01 \mathrm{~mm}$ dan stasiun LEM memiliki nilai peakAmp 7.400E03 micron meter atau 7.400E$00 \mathrm{~mm}$, yang berarti spektrum tersebut akan semakin terlihat apabila titik-titik pada sinyal tersebut semakin rapat.

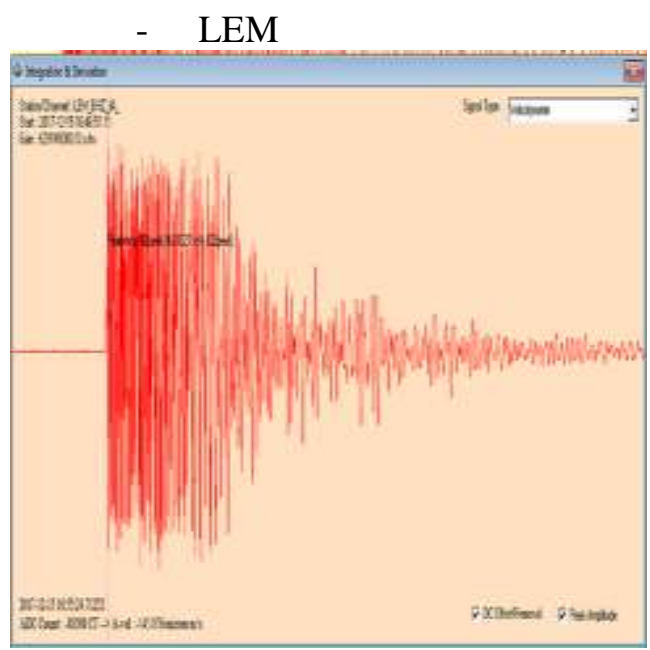

Gambar 9. Sinyal spektrum Velocity stasiun LEM

Berdasarkan gambar 8 dan 9 spektrum velocity pada stasiun KPJI memiliki nilai peakAmp sebesar 02peak atau $0.00726 \mathrm{~m} / \mathrm{s}$ dan pada stasiun LEM memiliki nilai peakAmp sebesar 02peak atau $0.01321 \mathrm{~m} / \mathrm{s}$. Pada spektrum velocity, semakin besar energi yang dikeluarkan maka semakin besar pula frekuensi yang dihasilkan.

Pada spektrum accelerometer stasiun KPJI memiliki nilai intensity sebesar 4.39093262731269MMI sedangkan pada stasiun LEM memiliki nilai intensity sebesar 5.1678009676682MMI. Pada tabel golongan skala MMI, nilai intensitas gempa bumi tersebut termasuk pada golongan IV untuk wilayah sekitar Karang Pucung, Cilacap (KPJI) dan golongan $\mathrm{V}$ untuk wilayah sekitar Lembang, Bandung (LEM).

\section{c. Acceleration}

\section{- KPJI}

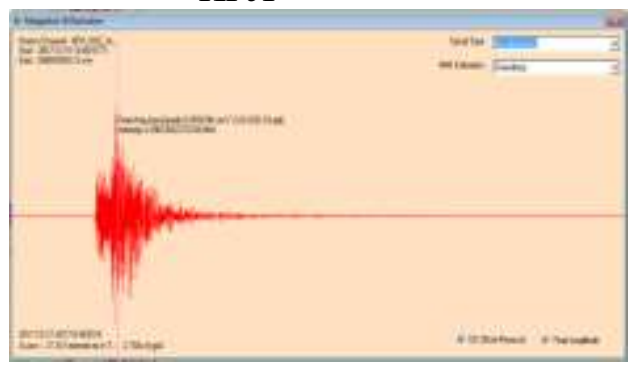

Gambar 10. Sinyal spektrum Acceleration stasiun KPJI

- LEM

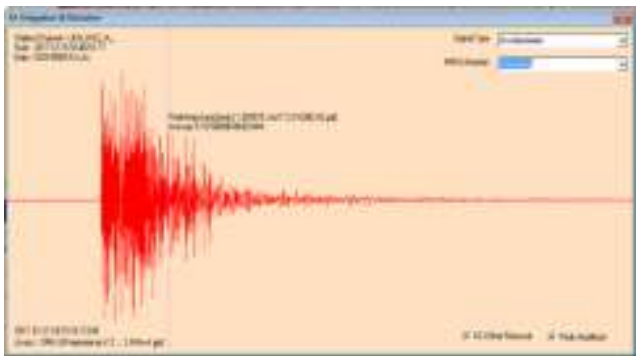

Gambar 11. Sinyal spektrum Acceleration stasiun LEM

Nilai intensitas tersebut sesuai dengan skala intensitas yang dikeluarkan oleh lembaga BMKG, dalam press release yang dikeluarkan pada tanggal 16 Desember 2017, disebutkan berdasarkan hasil analisis tingkat guncangan (shakemap), intensitas gempabumi ini berpotensi dirasakan sekitar Tasikmalaya berupa V-VI MMI dan di sekitar Jawa Barat lainnya berkisar adalah III-IV MMI. Hal ini sesuai dengan laporan masyarakat yang diterima BMKG bahwa gempabumi dirasakan cukup 
keras di Bandung, Kebumen, Karangkates II SIG-BMKG (III-IV MMI), Yogyakarta II SIGBMKG (III MMI), Jakarta, Depok II SIGBMKG (II-III MMI), Ngawi, Madiun, Nganjuk, Badung, Mataram I SIG-BMKG (II MMI). (BMKG, 2017)

\section{Analisis Pola Mekanisme Fokal}

Pada gambar 12 terlihat bagian yang berwarna merah (tekanan/compression) dan berwarna putih (tarikan/dilatation). Berdasarkan solusi mekanisme sumber gempa utama, dapat diketahui bahwa nilai orientasi sesar untuk bidang I mempunyai strike $56.5^{\circ}$, dip $70.5^{\circ}$, rake $172.7^{\circ}$ sedangkan pada bidang II mempunyai strike $149^{\circ}$, dip $83.1^{\circ}$, rake $19.7^{\circ}$. Dapat diketahui dari perpotongan kedua bagian, jenis sesar gempa tersebut adalah strike-slip fault (dextral)

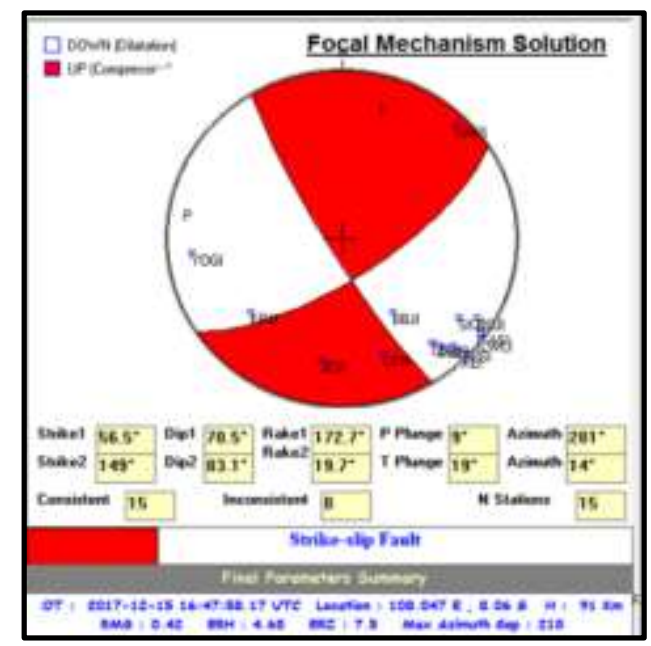

Gambar 12. Pola Mekanisme Fokal hasil pengolahan di JISView

\section{Analisis Perbadingan Parameter}

Pada tahap ini hasil perhitungan parameter gempa bumi dari software JISView akan dibandingkan sebagai validasi data dengan hasil parameter yang dikeluarkan oleh laman milik Geo Forschungs Zentrum (GFZ) Jerman (GFZ. 2017) dan United State Geological Survey (USGS) Amerika Serikat. (USGS. 2017)
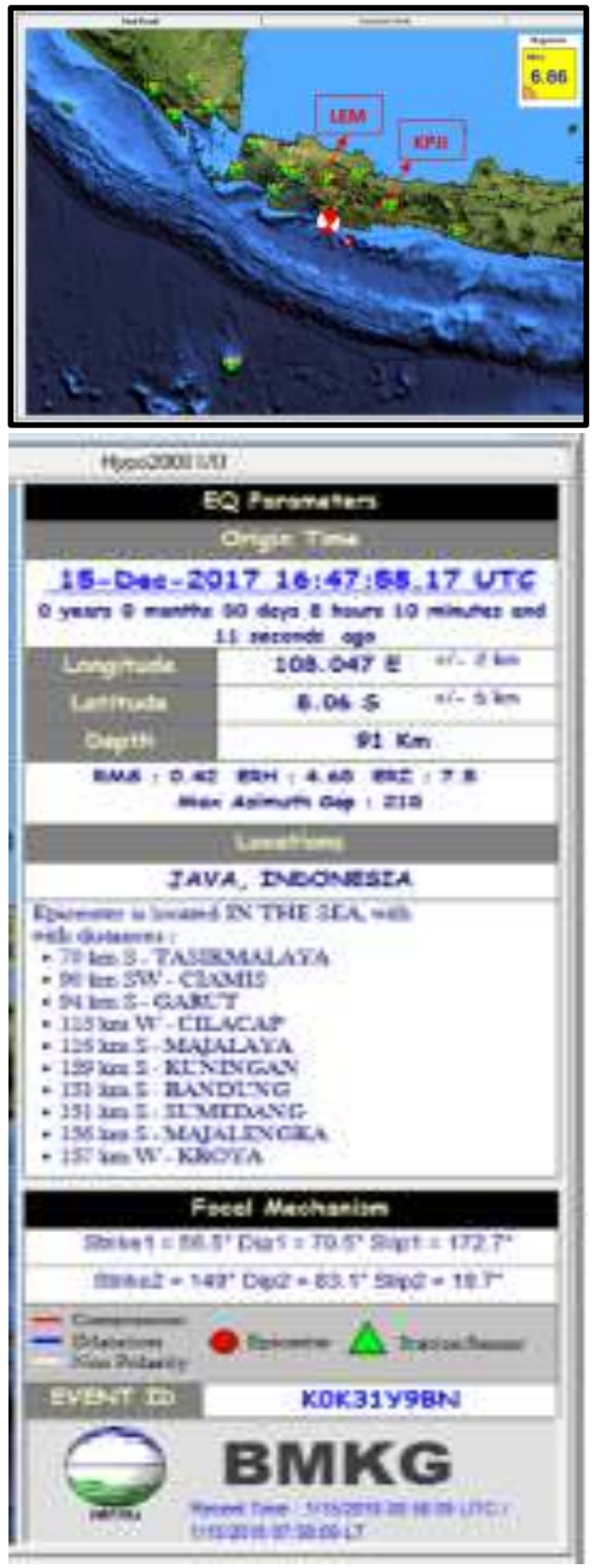

Gambar 13. Tampilan sistem informasi gempabumi untuk parameter gempa hasil pengolahan menggunakan JISView

Terdapat beberapa perbedaan dari hasil masingmasing data mekanisme sumber gempa bumi. Perbedaan ini bisa disebabkan karena alat yang digunakan untuk menganalisa sumber gempa pada tiap-tiap lembaga berbeda ataupun terdapat kesalahan pada saat memasukkan data oleh operator. Tapi terdapat satu parameter yang menunjukkan kesamaan, yaitu bentuk bola fokal dari data, ketiga sumber sama-sama menunjukkan hasil jenis sesar strike-slip fault 
(sesar mendatar), karena gerak sesar berarah sesuai arah jarum jam (Ibrahim \& Subardjo. 2005).

Kejadian gempa akibat thrust fault, normal fault, reverse slip dan strike slip yang terjadi sepanjang pertemuan lempeng dapat diklasifikasikan sebagai zona subduksi, yang mana dalam kasus ini, dengan kedalaman hiposenter sekitar 90-100 km, termasuk dalam gempa zona benioff jenis deep background (50-300 km). (Hutapea, B, M \& Mangape, I. 2009)

Tabel 1. Tabel 5.1 Perbandingan Parameter JISView, USGS, dan GFZ

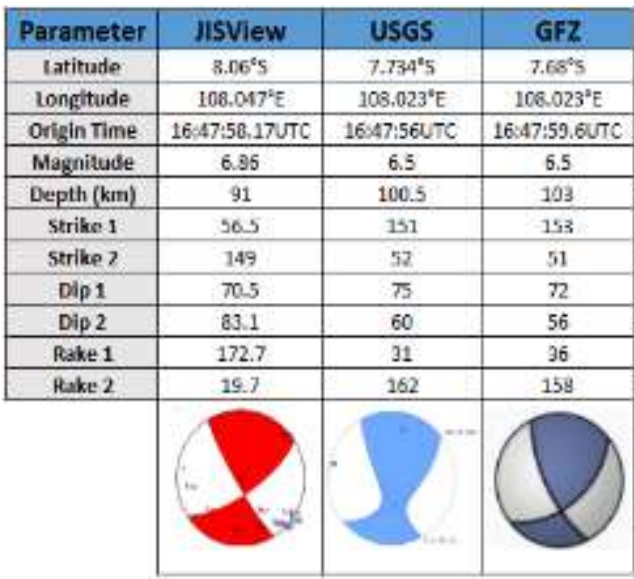

\section{KESIMPULAN}

Berdasarkan hasil pengolahan dan analisa, kesimpulan yang dapat diambil adalah sbb :

Nilai intensitas sinyal gempa yang didapat dari hasil pengolahan sesuai dengan data yang dikeluarkan oleh lembaga BMKG serta gempa berasal dari kedalaman antara 90-110 km yang mana terjadi akibat terjadinya pergeseran sesar, dengan jenis sesar yaitu strike-slip fault (dextral), dimana penyebab gempa berasal dari zona subduksi (zona benioff di deep background).

\section{SARAN}

- Perlu adanya penelitian lebih lanjut mengenai zona gempa di wilayah zona subduksi terutama di wilayan pulau jawa bagian Selatan.
- Perlu adanya pengembangan lebih lanjut terhadap perangkat JISView agar dapat menganalisis parameter gempa bumi dengan lebih presisi lagi.

\section{DAFTAR PUSTAKA}

Abidin, H. Z., Andreas, H., Gamal, M., Wirakusumah, A. D., Darmawan, D., Deguchi, T., \& Maruyama, Y. (2008). Land subsidence characteristics of the Bandung Basin, Indonesia, as estimated from GPS and InSAR. Journal of Applied Geodesy, 2(3), 167-177.

Badan Meteorologi Klimatologi dan Geofisika (BMKG). 2017. (http://www.bmkg.go.id), diakses pada tanggal 12 Januari 2018 pada pukul 09.44 WIB.

Badan Nasional Penanggulangan Bencana (BNPB). 2017. (https://bnpb.go.id/infografis/detail/update -gempa-bumi-tasikmalaya), diakses pada tanggal 18 Januari 2018 pada pukul 10.21 WIB.

ESDM. 2009. (http://www.vsi.esdm.go.id), diakses pada tanggal 25 Januari 2018 pada pukul 10.45 WIB.

GFZ. $2017 . \quad$ (https://geofon.gfzpotsdam.de/eqinfo), diakses pada tanggal 10 Januari 2018 pada pukul 08.30 WIB.

Hutapea, B, M \& Mangape, I. 2009. Analisis Hazard Gempa dan Usulan Ground Motion pada Batuan Dasar untuk Kota Jakarta. Jurnal Teoritis dan Terapan Bidang Rekayasa Sipil ITB. Vol.16 No. 3 Desember 2009.

Ibrahim, G \& Subardjo. 2005. Pengetahuan Seismologi. Badan Metereologi Klimatologi dan Geofisika (BMKG). Jakarta.

Ismiwati., T .2011. Mekanisme Fokus Gempa Bumi Mentawai 25 Oktober 2010. Skripsi. FST, Fisika, Universitas Islam Negeri Syarif Hidayatullah Jakarta

Nugraha J., Arifin J., Setyonegoro W., Hardy T., Susilanto P., 2013, "Pembangunan Sistem Monitoring Gempa bumi Jisview", Prosiding Seminar Tahunan Hasil-Hasil Penelitian dan Pengembangan Puslitbang $B M K G$, pp. 76-86. 
Sutrisna, M. 2015. Mikrozonasi Gempa Bumi Di Kota Cilacap Berdasarkan Data Pengukuran Mikrotremor. Universitas Pendidikan Indonesia (UPI).

Tim Pusat Studi Gempa Nasional, 2017, Peta Sumber Dan Bahaya Gempa Indonesia Tahun 2017, Kab. Bandung. Kementerian Pekerjaan Umum dan Perumahan Rakyat.

USGS. 2017. (https://earthexplorer.usgs.gov), diakses pada tanggal 10 Januari 2018 pada pukul 09.30 WIB.

Verstappen., H, TH. 2010. Indonesian Landforms and Plate Tectonics. Jurnal Geologi Indonesia, Vol 5 No. 3, September 2010. 197-207. 